\title{
UCR morphology and shock intensity
}

EDWARD D. GOODMAN, JAMES A. DYAL, OTTO ZIMSER AMD ARNOLO GOLUB 1

TEXAS CHRISTIAN UNIVERSITY

Nine shock levels of from 0.2 to $3.0 \mathrm{ma}$ were presented to five groups of albino rats. Group I received 5 levels of shock ranging from $0.2-1.0 \mathrm{ma}$. Group II received 9 levels of shock ranging from $0.2-3.0 \mathrm{ma}$. Shock intensities of $0.6 \mathrm{ma}, 1.6$ ma or 2.5 ma were given to groups III, IV, and V respectively. Each group received either 99 or 100 shock trials, each of $1 \mathrm{sec}$. duration. The response category curves (flinch, jump, prance, run, vocalization, and no response), relating shock intensity to proportion of total possible responses were in general agreement with previous research despite numerous procedural differences among the studies. The present study extended IICR morphology data considerably beyond previously used intensity levels.

Kimble (1955) and Trabasso \& Thompson (1962) used shock levels of 0.0-0.9 ma and categorized observations of UCR morphology to demonstrate a functional relationship between intensity of shock and UCR morphology. The resulting curves were similar in the two studies, even though different methods (method-of-limits vs. random order) of shock level presentation were used. The purpose of this study is: (1) to extend the range of shock levels to $3.0 \mathrm{ma}$; 2 ) to vary the number and range of shock levels given to S groups, and; (3) to extend the number of response categories used.

Method

Subjects and Experimenters. The Ss were 54 male Sprague-Dawley albino rats, approximately 90 days old at the start of the study. The Es were six graduate students from the Psychology Department at Texas Christian University.

Apparatus. The apparatus was a black, glass front box, 24 in. high $\times 33.4$ in. long $\times 4.5$ in. wide, with grids spaced .5 in. apart, perpendicular to the long axis. Grid shock of 1 sec. duration was delivered by a Model E 1064 GS Grason-Stadler shock generator. Grid shock intensities of $0.2,0.4,0.6,0.8,1.0,1.6,2.0,2.5$ and 3.0 ma were presented by a manual intensity selector switch. The intershock interval was controlled by a Farmer CK electric timer.

Procedure. Group I (18 Ss) received five levels of shock $0.2,0.4,0.6,0.8$, and $1.0 \mathrm{ma}$ randomized in 10 blocks of 10 for 100 shocks. Group II (18 Ss) received nine levels of shock $0.2,0.4,0.6,0.8,1.0,1.6,2.0,2.5$, and $3.0 \mathrm{ma}$ randomized for levels in 11 blocks of nine trials, for a total of 99 shocks. Groups III, IV, and V, (six Ss in each group) each received 100 trials at a single intensity of either $0.6,1.6$, or 2.5 ma respectively. The responses to shock observed during the 1 sec. shock period were categorized as follows: (a) prance (P), lifting one or more feet with at least one foot always in contact with a grid, and making a lateral movement of less than 6 in. (responses placed in this category were usually characterized by rapid, jerky body movements often with the back arched); (b) jump (J), all four feet leaving the grid at the same time; (c) run (R), a lateral movement of $6 \mathrm{in.}$ or more; (d) flinch (F), any observable response to shock not included in the jump, prance,
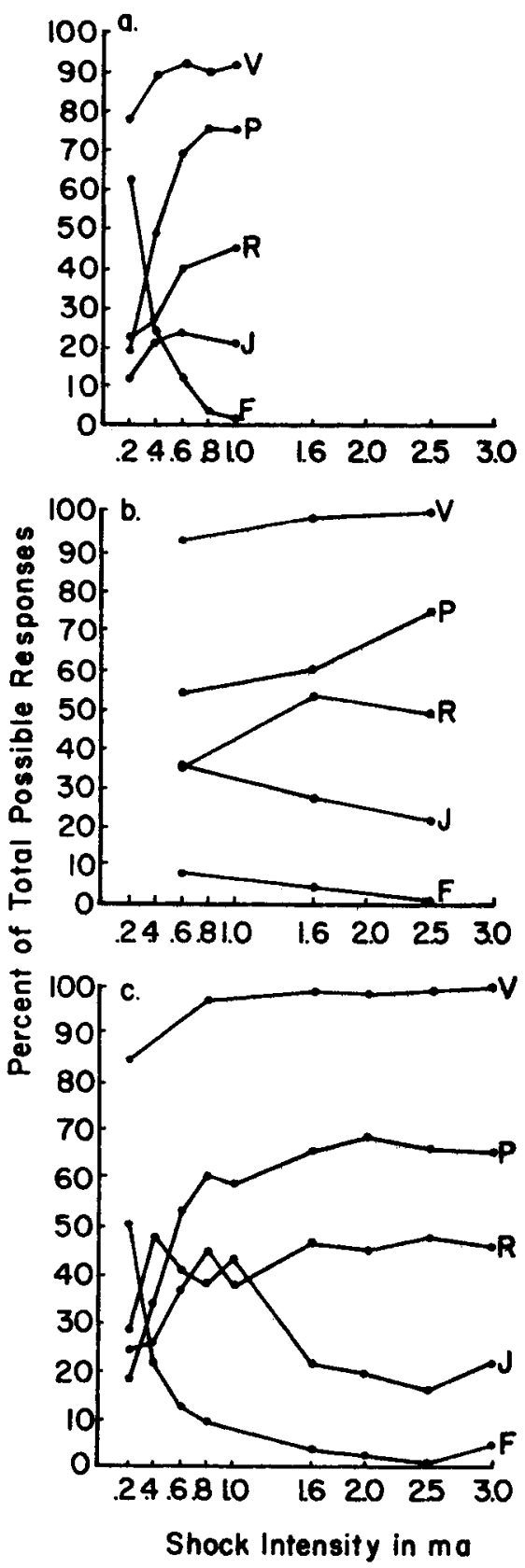

Fig. 1. A, Group I data; B, Group II data; C, Group III, IV, and $V$ data plotted on a single graph. 
or run categories; (e) no response (N), no observable response to shock; ( $f$ ) vocalization $(V)$, any audible sound made by the $S$.

\section{Resulis and Discussion}

Under Group II (extended range) conditions, F responses (as measured by the proportion of responses emitted to the total possible number of responses in a given category, i.e., 99 or 100) decrease in frequency with increasing intensity. An $F$ test ( $F$ treatment $=17.72$, F $.01=2.66$; $\mathrm{df}=8 / 136$ ) showed this trend (linear, quadratic and cubic trends: $F=91.3, F=35.58$, and $F=12.95 ; \quad F .01=6.85, \mathrm{df}=1 / 136)$ to be significant. An $F$ test $(F=28.93, F .01=2.66, d f=8 / 136)$ over the combined $\mathrm{P}, \mathrm{T}$, and $\mathrm{R}$ responses (shuttle compatable) revealed a significant increasing frequency trend (linear, quadratic and cubic trends: $F=144.13, F=68.98$, $F=11.99 ; \quad F .01=6.85, \mathrm{df}=1 / 136$ ) with increase in shock intensity.

Comparison of Fig. 1a, b and $c$ at all intensity levels above $1.0 \mathrm{ma}$ indicates that there is a consistent ordering of response categories $(N, F, J, R, P$, and $V$, from least to most frequent) under each of the five treatment groups. The $\mathrm{P}$ and $\mathrm{R}$ response curves appear to be negatively accelerated increasing monotonic functions, asymptotic by $2.0 \mathrm{ma}$, with the $P$ responses occurring more frequently at all intensities above $0.2 \mathrm{ma}$ for all group treatment conditions. Inspection of the $\mathrm{J}$ response curves indicates that $J$ responses are curvilinearly related to shock intensity, when the range is extended above the $.9 \mathrm{ma}$ maximum used by Kimble (1955), and Trabasso \& Thompson (1962).

In order to test for possible shock adaptation effects to 100 shock trials of uniform intensity, a correlated
" $t$ " test was run on the $F$ responses and on the shuttle compatable responses ( $P, R$ and $J$ combined) over the first and last 10 trials for Group IV, and first and last 25 trials for Group V. None of the " $t$ "' values approached significance at the .05 level, indicating that there was no significant adaptation effects to shock reflected by these measures.

The present results for Group I, reflected in Fig. 1a, are consistent with those of Kimble (1955) and Trabasso \& Thompson (1962) in that over similar intensity ranges the ordinal relationship of response curves is maintained, and the inflection points occur at similar locations. These similarities were found despite (a) differences in apparatus configuration, (b) different psychophysical methods of shock level presentation, (c) differences in range and number of levels of shock given to Ss, (d) unequal total number of trials administered, (e) within S vs. between Ss design, (f) age, sex, and strain differences, and (g) multiple experimenters. The data for extended shock range groups II, III, IV and V as indicated in Fig. $1 \mathrm{~b}$ and $\mathrm{c}$, show no reversal in curve order but do reflect systematic changes with increase in intensity.

\section{References}

Kimble, G. A. Shock intensity and avoidance learning. J. comp. physiol. Psychol., 1955, 48, 281-284.

Trabasso, T. R., \& Thompson, R. W. Shock intensity and unconditioned responding in a shuttle box. J. exp. Psychol., 1962,63, 215-216.

\section{Note}

1. The authors wish to thank Don Walker, Marcia Duke, Jim Shapiro, and Robert Marrone who helped collect the data for this experiment. 